Supporting Information of

\title{
Profiling Aerosol Liquid Water Content Using a Polarization Lidar
}

Wangshu Tan ${ }^{1}$, Yingli $\mathrm{Yu}^{1}$, Chengcai Li*, ${ }^{*}$, Jing $\mathrm{Li}^{1}$, Ling $\mathrm{Kang}^{2}$, Huabin Dong ${ }^{2}$, Limin Zeng ${ }^{2}$, Tong $\mathrm{Zhu}^{2,3}$

${ }^{1}$ Department of Atmospheric and Oceanic Sciences, School of Physics, Peking University, Beijing 100871, China

${ }^{2}$ State Key Joint Laboratory of Environmental Simulation and Pollution Control, College of Environmental Science \& Engineering, Peking University, Beijing 100871, China

${ }^{3}$ Beijing Innovation Center for Engineer Science and Advanced Technology, Peking University, Beijing 100871, China

*Correspondence to: Chengcai Li (ccli@pku.edu.cn)

Number of pages: 6

Number of figures: 5

Number of tables: 0 
S1 Relationship between particle linear depolarization ratio $\delta_{\mathrm{p}}$ and relative humidity.

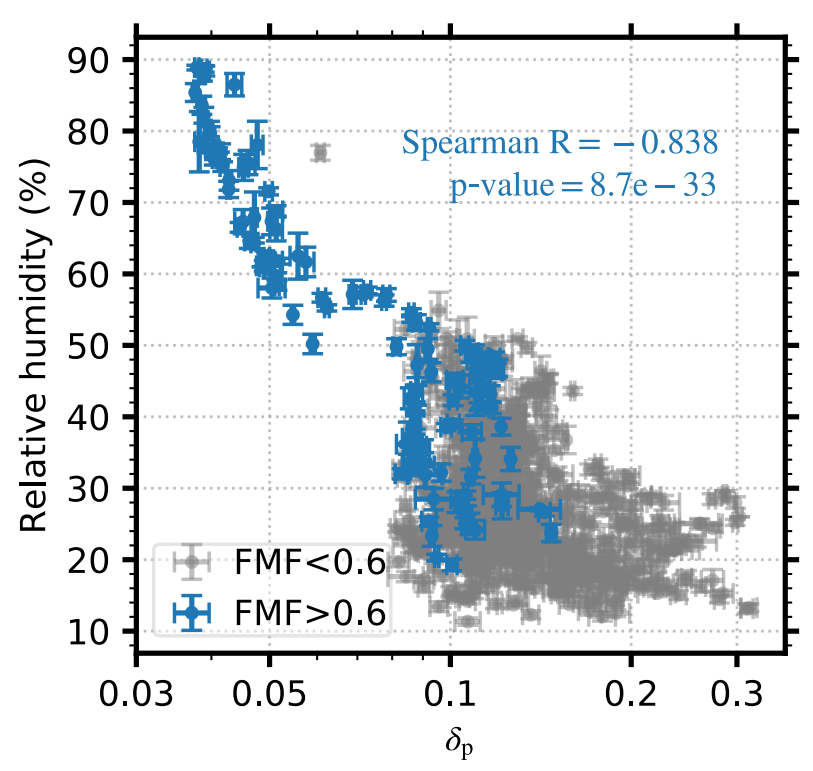

Figure S1. Relationship between particle linear depolarization ratio $\delta_{\mathrm{p}}$ and relative humidity. The blue dots represent conditions when the fine-mode fraction (FMF) exceeds 0.6 , and the gray dots represent conditions when the FMF is below 0.6. The error bars denote one standard deviation.

S2 Dependencies of particle linear depolarization ratio $\delta_{p}$ on dry mass fractions of dust, organic matter, and water-soluble inorganic species

Dry mass fractions of organic matter $\left(\mathrm{OM} ; f_{\mathrm{OM}, \mathrm{dry}}\right)$, water-soluble inorganic species $\left(f_{\mathrm{IO}, \mathrm{dry}}\right)$, and dust $\left(f_{\text {dust,dry }}\right)$ of particles in ambient environment are defined as:

$$
\begin{aligned}
& f_{\mathrm{OM}, \mathrm{dry}}=\frac{m_{\mathrm{OM}}}{m_{\mathrm{PM} 10}} \\
& f_{\mathrm{IO}, \mathrm{dry}}=\frac{m_{\mathrm{Chem}}-m_{\mathrm{OM}}}{m_{\mathrm{PM} 10}}
\end{aligned}
$$


$f_{\text {dust,dry }}=\frac{m_{\text {dust }}}{m_{\mathrm{PM} 10}}=\frac{m_{\mathrm{PM} 10}-m_{\mathrm{Chem}}}{m_{\mathrm{PM} 10}}$.

where the variables are defined the same as them in the paper.

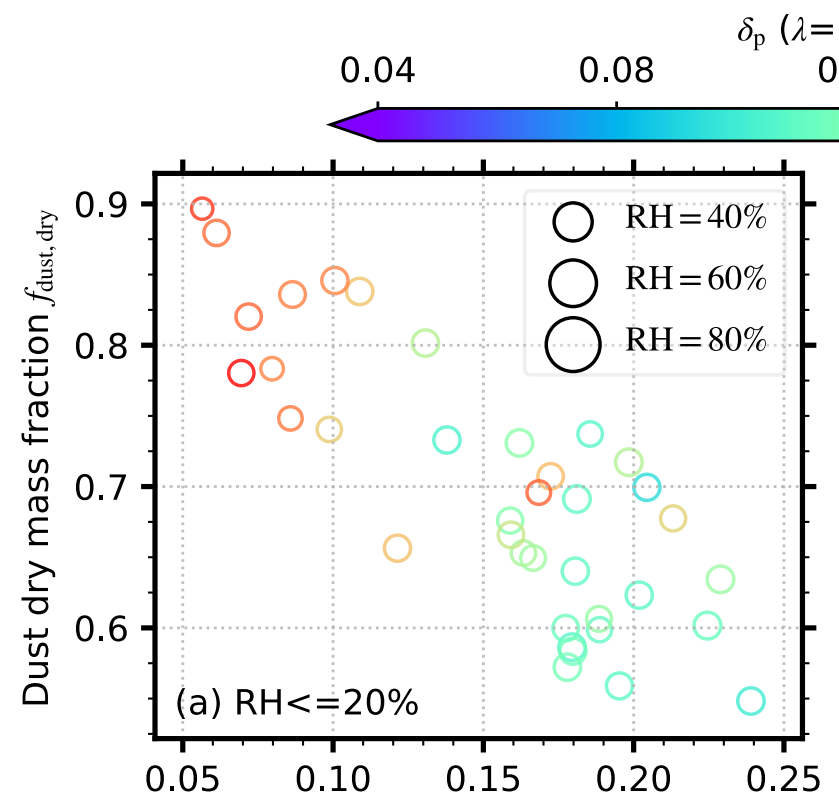

Organic matter dry mass fraction $f_{\mathrm{OM} \text {, dry }}$
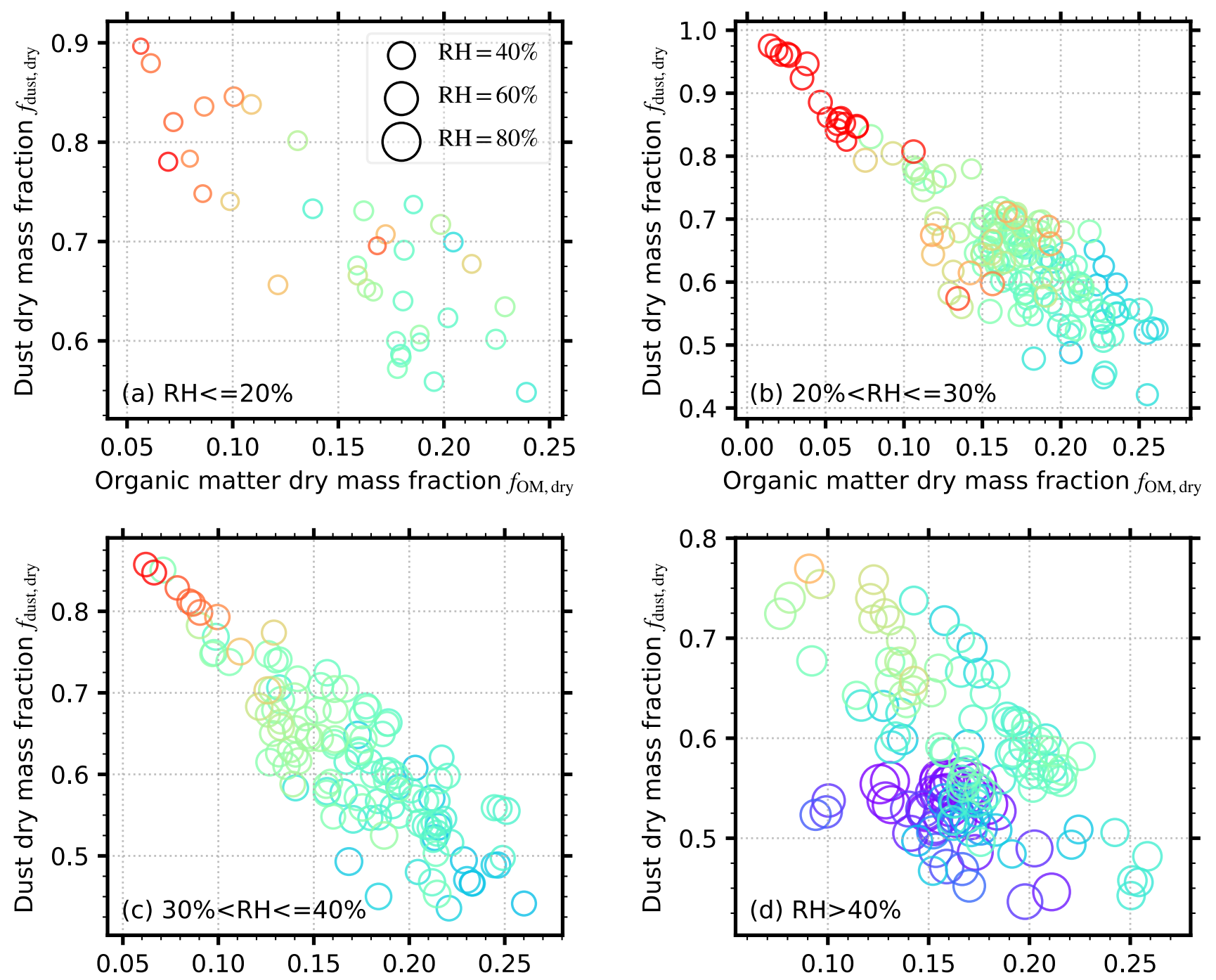

Organic matter dry mass fraction $f_{\mathrm{OM} \text {, dry }}$

Organic matter dry mass fraction $f_{\mathrm{OM}}$, dry

Figure S2. Influence of organic matter dry mass fraction $f_{\mathrm{OM}, \mathrm{dry}}$ and dust dry mass fraction $f_{\text {dust,dry }}$ of ambient aerosols on $\delta_{\mathrm{p}}$ at $532 \mathrm{~nm}$ under conditions of (a) relative humidity (RH) below 20\%, (b) $\mathrm{RH}$ 
above $20 \%$ and below $30 \%$, (c) RH above $30 \%$ and below $40 \%$, and (d) $\mathrm{RH}$ above $40 \%$. The color of the circle represents the value of $\delta_{\mathrm{p}}$, and the size of the circle shows the RH.

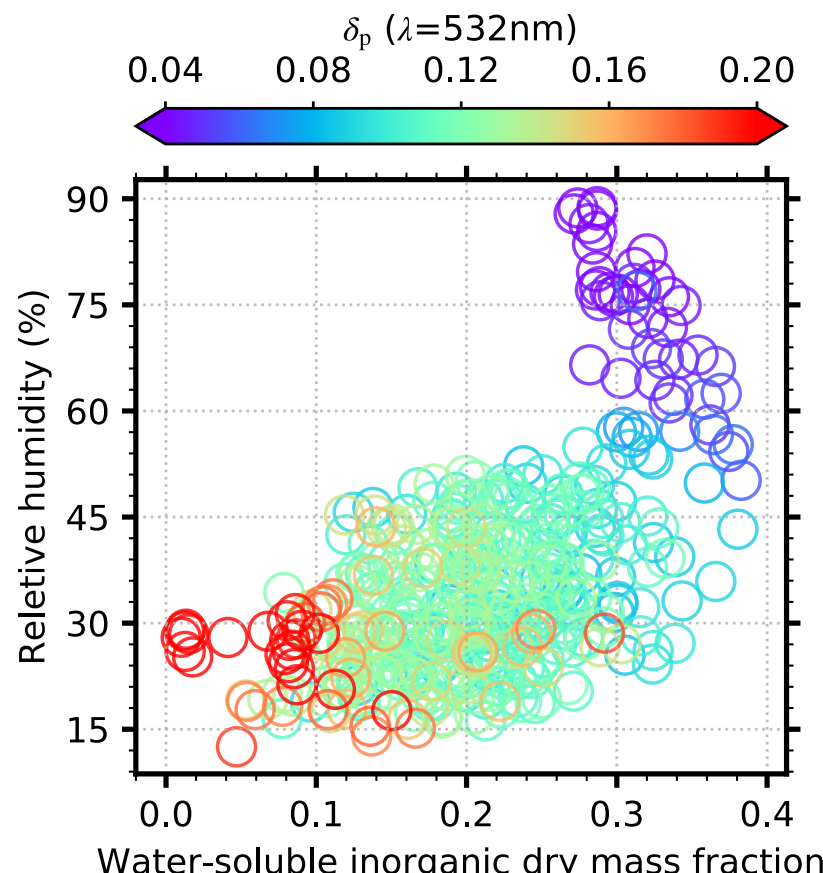

Figure S3. Influence of water-soluble inorganic dry mass fraction and ambient relative humidity on $\delta_{\mathrm{p}}$ at $532 \mathrm{~nm}$ under conditions The color of the circle represents the value of $\delta_{\mathrm{p}}$.

\section{S3 Mie calculation}

The calculation is carried out by split particles into fine and coarse mode. The split radius of the fine and the coarse mode is $576 \mathrm{~nm}$. The refractive indices of the fine mode are set to be $1.535+0.005 i$ for $355 \mathrm{~nm}$ and $1.53+0.006 i$ for $532 \mathrm{~nm}$. The density of the fine mode is $1.76 \mathrm{~g} \mathrm{~cm}^{-3}$. For the coarse mode, the refractive indices are $1.54+0.008 i$ and $1.53+0.0065 i$ for 355 and $532 \mathrm{~nm}$ respectively. The density of the coarse mode is $2.6 \mathrm{~g} \mathrm{~cm}^{-3}$. The refractive indices and densities are also implemented in the calculation of linear depolarization ratio of spheroid particles. 


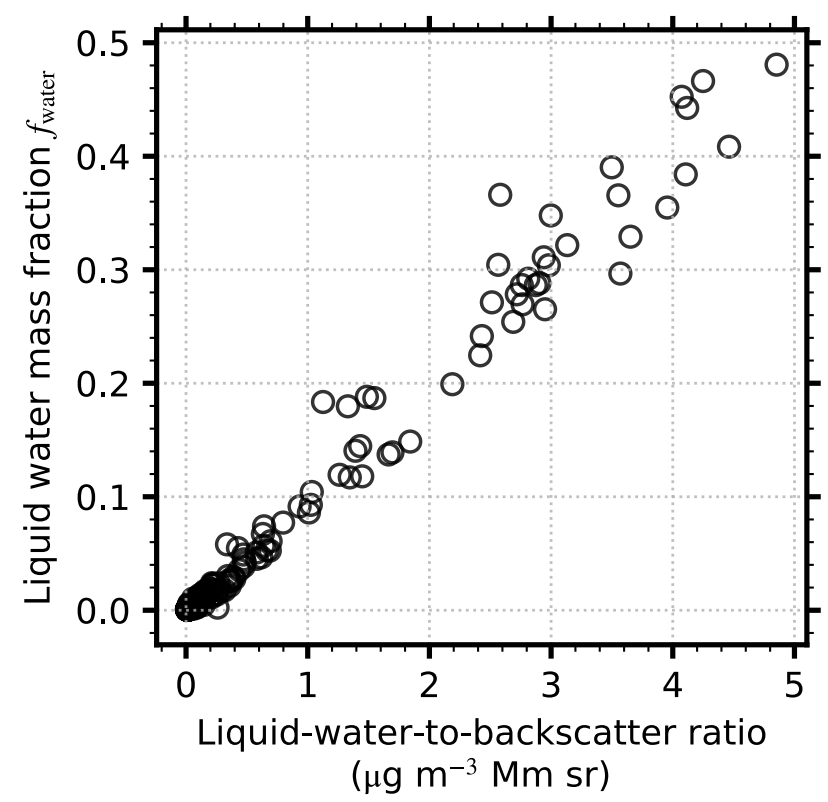

Figure S4. Relationship between liquid-water-to-backscatter ratio (defined as the ratio of liquid water mass to particle backscatter coefficient) and aerosol liquid water mass fraction $f_{\text {water }}$.

\section{S5 Lidar-based overview of the case study period}

Figure S3 shows the range corrected signal (RCS) and volume linear depolarization ratio (VLDR) from a collocated micro pulse lidar (MPL). Dust appeared in the upper layer. 


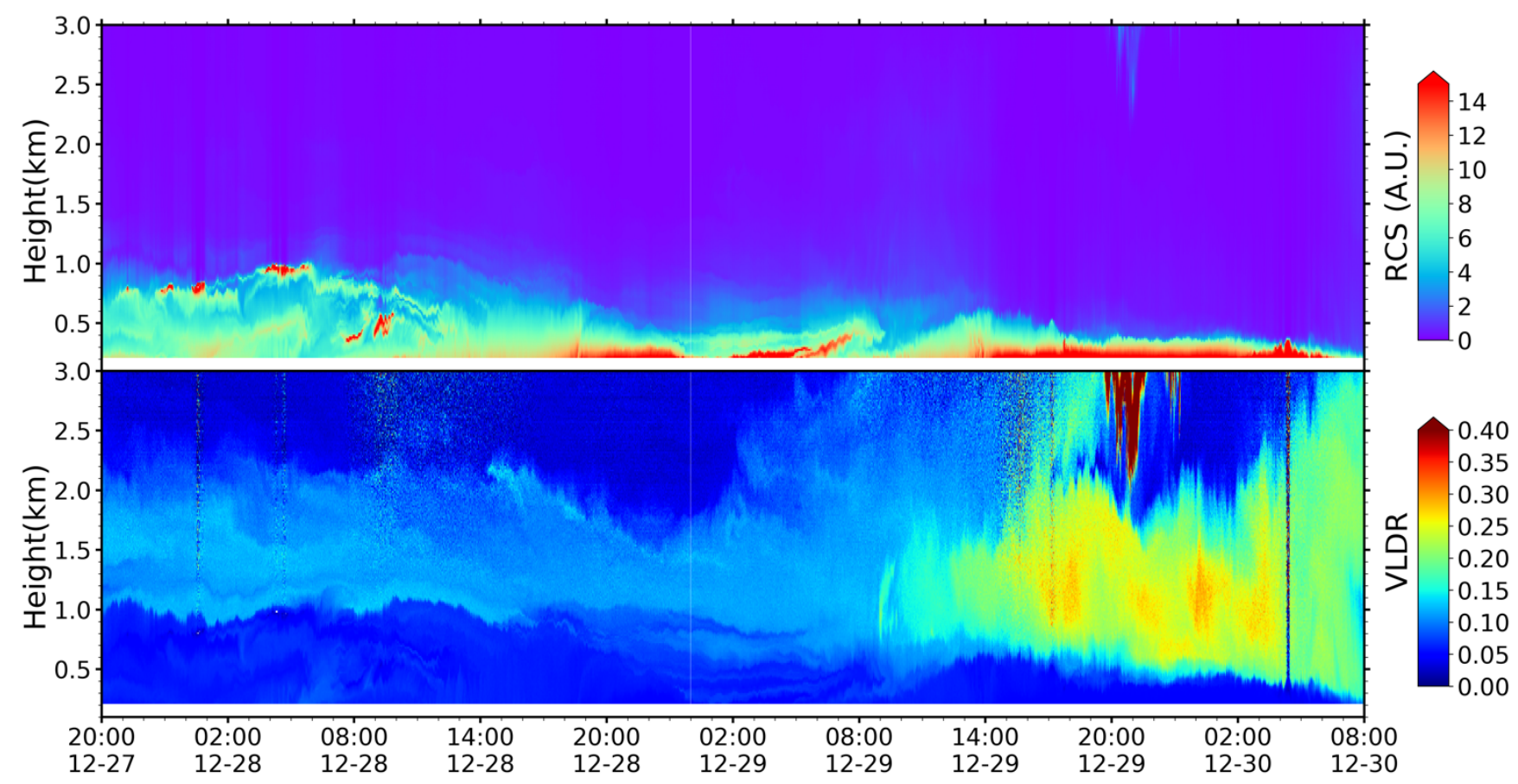

Figure S5. Range corrected signal (RCS) of $532 \mathrm{~nm}$ (upper panel) and volume linear depolarization ratio (VLDR) of $532 \mathrm{~nm}$ (lower panel) with temporal and vertical resolution of $1 \mathrm{~min}$ and $15 \mathrm{~m}$ during November 27 20:00, 2017 to November 30 8:00, 2017. 